\title{
DESIGN AID FOR CONTINUOUS BEAMS
}

\author{
S.N. Khuda ${ }^{(1)}$ and A.M.M.T. Anwar ${ }^{(2)}$
}

1. Lecturer, Department of Civil Engineering, Military Institute of Science and Technology

E-mail: sarkarnoorekhuda@yahoo.com

2. Professor, Department of Civil Engineering, Bangladesh University of Engineering and Technology

E-mail: tanwar@ce.buet.ac.bd

\begin{abstract}
Analysis and design of beam is still an important part in Structural Engineering practice. As a major component in structure, it demands due attention and accuracy. At the same time engineers need to achieve economy in time and cost in the design of beams. To assist designers moment coefficients are developed for continuous beams in this work. Existing ACI moment coefficients are applicable only under certain conditions and have some limitations. This study is an attempt to develop moment coefficients for beams which will be applicable beyond ACI limitations. Comparison of developed coefficients with corresponding ACI coefficients has been done and a satisfactory agreement is found. However, ACI coefficients are found to be conservative. Additionally design tables are developed for selection of RC beam section and reinforcement when design bending moment and shear are available. SAP2000 has been used for analysis of beams during the study. Models are used to generate exact moment coefficients for beams of different span ratios and spans under uniform loading. The moment coefficients and design tables generated in this work will be useful for practicing engineers for quick design.
\end{abstract}

KEY WORDS: Moment Coefficient; Shear; Continuous Beam; Uniform Loading.

\subsection{INTRODUCTION}

The few things that represent a civilization include structural establishment of that time. With advancement of time human inventions have made miracles a simple math. With time, beam column structure is becoming more familiar, convenient and reliable considering time and cost. An approximate method of analysis based either on careful sketches of the shape of the deformed structure under load or on moment coefficients still provides a means for rapid estimation of internal forces and moments. Such estimates are useful in preliminary design and checking more exact solutions for gross errors that might result from input errors. The moment coefficients developed earlier has been supporting engineers so far but still there are lot of dissatisfaction as they impose few rigid restrictions for the designers. Engineering in general practice attempt to understand the response of beams on loading. Because of complicated nature on the distribution of loads, the supporting structural system may differ substantially from that of a set of beams. The behavior of beams under differing loading system, support conditions accompanied with different shapes and sizes has yet large extents to go. Before development of proper approach to analysis and design of various shapes of beams, most of the beams in building design and other types of structure were rectangular. This study represents an honest effort to go out of the set restrictions in case of moment coefficients and present a set of coefficients which stands out of the restrictions. For studying the behavior of beams and develop moment coefficients a well developed program SAP2000 was used. A set of beams of different spans and varying span ratio were analyzed.

\subsection{STUdy SIGNIFICANCE}

Beams with more than one span are called continuous beams, because they continue over the intermediate spans. Continuous beams are most common in bridges and building structures. Again, the span lengths may be unequal and the moment of inertia of the cross section may be different form one span to another. The analysis of such beams by the force method using reactions as redundant would require the computation of a large number of deflections or slopes in a basic beam with several variations in moment of inertia of its cross-section. Again there are some other processes to analyze the beams for moments, slopes etc. 


\subsection{NECESSITY OF APPROXIMATE ANALYSIS}

In spite of the development of refined methods for the analysis of beams and frames increasing attention is being paid to approximate method of analysis. There are several reasons for this. Prior to performing a complete analysis of an indeterminate structure, it is necessary to estimate the proportions of its members in order to know their relative stiffness, upon which the analysis depends. These dimensions can be obtained on the basis of approximate analysis. Also, even with the availability of computers, most engineers find it desirable to make a rough check of results, using approximate means, to detect gross errors. Further, for structures of minor importance, it is often satisfactory to design on the basis of results obtained by rough calculation. For these reasons, many engineers at some stage in design process estimate the values of moments, shears, and thrusts at critical locations, using approximate sketches of the structure deflected by its loads.

\subsection{EXISTING MOMENT COEFFICIENT FOR BEAMS}

ACI code 8.3 includes expressions that may be used for the approximate calculation of maximum moments and shears in continuous beams and one way slabs. The expressions for moment take the form of coefficient multiplied by $\mathrm{W}_{\mathrm{u}}\left(\mathrm{L}_{\mathrm{n}}\right)^{2}$, where $\mathrm{W}_{\mathrm{u}}$ is the total factored load per unit length of the span and $L_{n}$ is the clear span from face of supports for positive moment or the average of the two adjacent clear spans for negative moment. Shear is taken equal to a coefficient multiplied by $\mathrm{W}_{\mathrm{u}} \mathrm{L}_{\mathrm{n}}$. The moment coefficients, found in ACI code 8.3.3 are reprinted in a table later on in this paper.

The ACI moment coefficients were derived by elastic analysis, considering alternative placement of live load to yield maximum negative or positive moments at the critical sections. They are applicable within the following limitations:

1. There are two or more spans.

2. Spans are approximately equal, with the longer of two adjacent spans not greater than the shorter by more than 20 percent.
3. Loads are uniformly distributed.

4. The unit live load does not exceed 3 times the unit dead load

5. Members are prismatic.

\subsection{GENERATION OF MOMENT COEFFICIENT}

For the present study of continuous beam analysis and design SAP2000 software has been used. For analysis cases, Firstly, beams of two spans, three spans, four spans and five spans are considered. Verification has also been performed outside ACI permitted range of span considering longer span greater than $20 \%$ of the adjacent shorter span. Various span ratios have been set for analysis of beams. Considering span ratio and number of span parameters has been set for the analysis case. Moment at different points of the beam has been found using SAP2000 software. Moment coefficient has been obtained by dividing the moment by the square of adjacent span length. To perform this calculation a computer based spreadsheet program has been written in EXCEL software. For design of beam both for moment and shear parameters has been set considering loads from slabs of general range. The lower limit has been set considering loads from a 10'x10' slab and the upper limit has been set considering a 32'x32' slab. Finally design of the beam has been done using SAP2000 software.

\subsection{PARAMETERS OF STUDY}

Assumed variation of parameters for analysis of continuous beams for moment coefficients:

No of spans $=2$ to 5

Span length for the first span $=10 \mathrm{ft}$

Uniformly distributed load all over the beam $=1$

$\mathrm{kip} / \mathrm{ft}$

Span ratio $=1$ to 2

Variation in span ratio between two spans $=0.2$

Cross-section of the beam $=10$ in X18 in

Self weight of the beam is assumed to be negligible. 
Assumed variation of parameters for design of

beams for moment:

Simply supported beam

Span length $=20 \mathrm{ft}$

Width of beam cross section $=10$ in

Depth of beam cross section $=12$ in to 30 in @ 3 in

Strength of concrete, $\mathrm{f}_{\mathrm{c}}{ }^{\prime}=3 \mathrm{ksi}$

Strength of steel, $\mathrm{f}_{\mathrm{y}}=60 \mathrm{ksi}$

Uniformly distributed load (kip/ft), all over the beam to create desired moment.

Assumed variation of parameters for design of beams for shear:

Simply supported beam

Span length $=20 \mathrm{ft}$

Width of beam cross section $=10$ in

Depth of beam cross section $=12$ in to 30 in @3 3

in

Strength of concrete, $\mathrm{f}_{\mathrm{c}}{ }^{\prime}=3 \mathrm{ksi}$

Strength of steel, $\mathrm{f}_{\mathrm{y}}=60 \mathrm{ksi}$

Uniformly distributed load (kip/ft), all over the beam to create desired shear.

\subsection{FINDINGS}

From the study, moment coefficient (C) has been generated for two span, three span, four span and five span continuous beams with varying span ratio. These moment coefficients are given in Table 1 where, moment coefficients for a selected number of span ratios are shown. As all the first span is taken to be $10 \mathrm{ft}$, for higher span number and span ratio, the beam span length exceeds the maximum practical limit. Therefore, for four span and five span beams lower span ratio has been considered. Graph of moment coefficient for span ratio variation has been developed (Fig 1- Fig 9). For graphical representation only five span beams are considered. The span ratio variation is provided shown in legend. Beams are also been designed for moment and shear shown in Table 2 and Table 3. Finally, a comparison between the generated moment coefficients and the available ACI moment coefficients has been shown in Table 4 . The variation of moment coefficient for crosssection variation is given in Table 5 .

General findings are appeared bellow:
- Development of moment coefficient (C) for two span, three span, four span and five span continuous beam with various span ratio.

- Table of moment coefficient (C) for two span, three span, four span and five span continuous beam and various span ratio (Table $1)$.

- Graph of moment coefficient (C) against various span ratio.

- Design of beam for moment (Table 2).

- Design of beam for shear (Table 3).

- Comparison of generated data with available data (Table 4).

- Variation of moment coefficient for cross section variation (Table 5). 


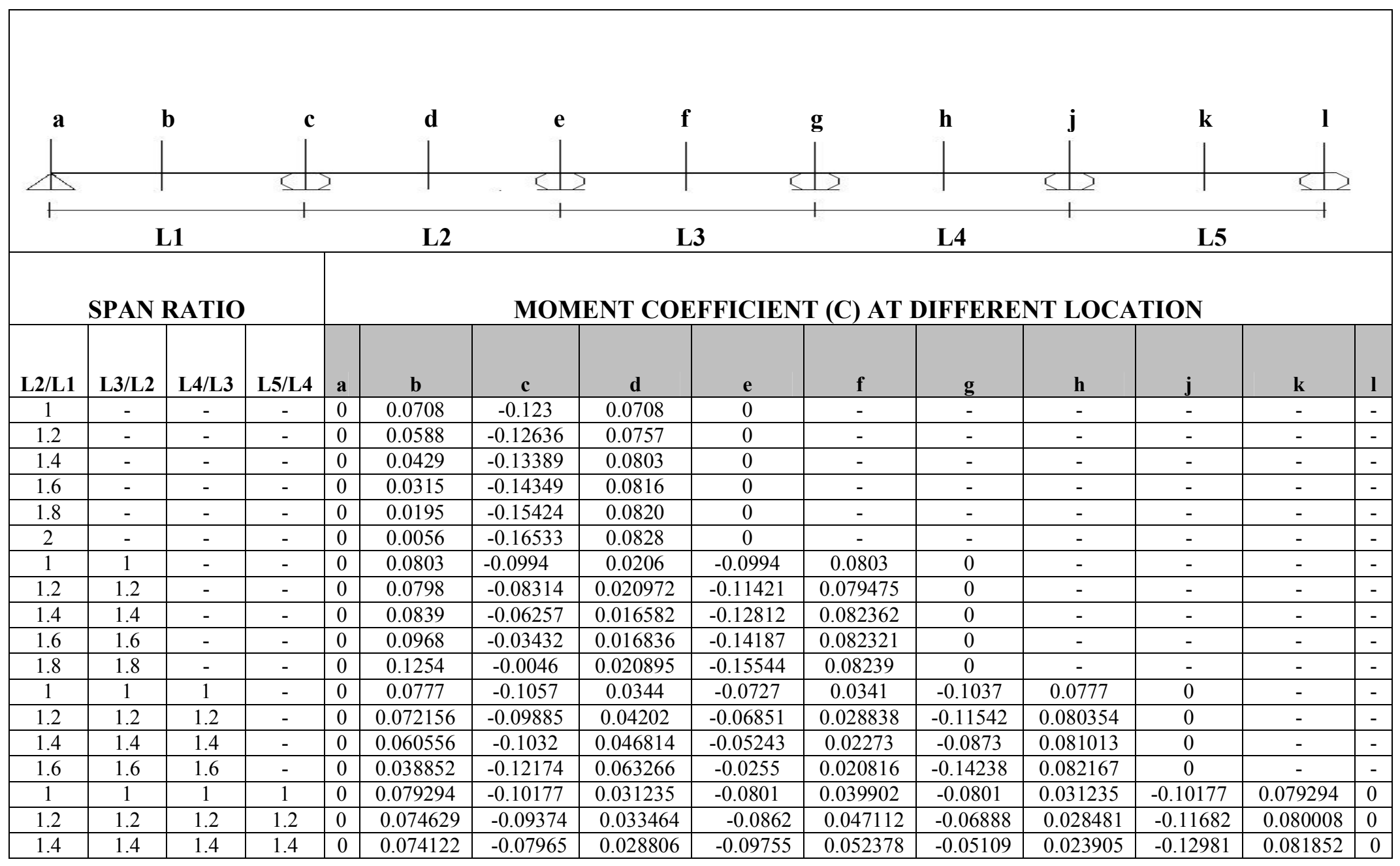

Table 1: Various Moment Co-efficient

Moment coefficient (C) in continuous beams for different span ratio

Moment, $\mathrm{M}=\mathrm{CWL}^{2}$

Where, $\mathrm{W}=$ Uniform load; $\mathrm{L}=$ Respective span length for mid span moment or average of adjacent span lengths for Support moments 


\begin{tabular}{|c|c|c|c|c|c|c|c|c|c|c|c|c|c|c|}
\hline \multirow{4}{*}{$\begin{array}{c}\text { MOMENT, } \\
\mathrm{k}-\mathrm{ft}\end{array}$} & \multicolumn{14}{|c|}{ CROSS SECTION } \\
\hline & \multicolumn{2}{|c|}{$10 " \mathrm{X} 12^{\prime \prime}$} & \multicolumn{2}{|c|}{$10 " X 15 "$} & \multicolumn{2}{|c|}{$10 " \mathrm{X18"}$} & \multicolumn{2}{|c|}{$10 " \mathrm{X} 21 "$} & \multicolumn{2}{|c|}{$10 " \times 24$} & \multicolumn{2}{|c|}{$10 " \mathrm{X} 27 "$} & \multicolumn{2}{|c|}{$10 " \mathrm{X30"}$} \\
\hline & \multicolumn{14}{|c|}{ REINFORCEMENT, $\mathrm{in}^{2} / \mathrm{ft}$} \\
\hline & BOTTOM & TOP & BOTTOM & TOP & ВОTТОМ & TOP & BOTTOM & TOP & BOTTOM & TOP & BOTTOM & TOP & BOTTOM & TOP \\
\hline 20 & 0.66 & - & 0.48 & - & 0.53 & - & 0.45 & - & 0.38 & - & 0.33 & - & 0.31 & - \\
\hline 46 & 1.73 & 0.011 & 1.18 & - & 0.95 & - & 0.8 & - & 0.74 & - & 0.78 & - & 0.72 & - \\
\hline 72 & Fail & - & 2.01 & - & 1.56 & - & 1.29 & - & 1.07 & - & 0.93 & - & 0.9 & - \\
\hline 98 & Fail & - & 2.73 & 0.59 & 2.25 & - & 1.82 & - & 1.49 & - & 1.29 & - & 1.19 & - \\
\hline 124 & Fail & - & Fail & - & 2.91 & 0.32 & 2.4 & - & 1.94 & - & 1.66 & - & 1.53 & - \\
\hline 150 & Fail & - & Fail & - & 3.47 & 0.91 & 3.04 & 0.01 & 2.41 & - & 2.05 & - & 1.88 & - \\
\hline 176 & Fail & - & Fail & - & 4.03 & 1.49 & 3.52 & 0.51 & 2.92 & - & 2.45 & - & 2.25 & - \\
\hline 202 & Fail & - & Fail & - & Fail & - & 4.01 & 1.02 & 3.47 & - & 2.88 & - & 2.63 & - \\
\hline 228 & Fail & - & Fail & - & Fail & - & 4.49 & 1.52 & 3.89 & 0.35 & 3.33 & - & 3.03 & - \\
\hline 254 & Fail & - & Fail & - & Fail & - & Fail & - & 4.29 & 0.76 & 3.82 & - & 3.44 & - \\
\hline 280 & Fail & - & Fail & - & Fail & - & Fail & - & 4.69 & 1.18 & 4.23 & 0.2 & 3.88 & - \\
\hline 306 & Fail & - & Fail & - & Fail & - & Fail & - & 5.08 & 1.59 & 4.58 & 0.56 & 4.34 & 0.02 \\
\hline 358 & Fail & - & Fail & - & Fail & - & Fail & - & Fail & - & 5.5 & 1.67 & 5.02 & 0.72 \\
\hline 384 & Fail & - & Fail & - & Fail & - & Fail & - & Fail & - & 5.87 & 2.06 & 5.36 & 1.07 \\
\hline 410 & Fail & - & Fail & - & Fail & - & Fail & - & Fail & - & Fail & - & 5.69 & 1.42 \\
\hline 436 & Fail & - & Fail & - & Fail & - & Fail & - & Fail & - & Fail & - & 6.03 & 1.78 \\
\hline 462 & Fail & - & Fail & - & Fail & - & Fail & - & Fail & - & Fail & - & Fail & - \\
\hline
\end{tabular}

Table 2: Design of Beam for Moment 


\begin{tabular}{|c|c|c|c|c|c|c|c|}
\hline \multirow{3}{*}{$\begin{array}{c}\text { SHEAR, } \\
\mathrm{k}\end{array}$} & \multicolumn{7}{|c|}{ CROSS SECTION } \\
\hline & $10 " x 12 "$ & $10 " x 15 "$ & $10 " x 18 "$ & $10 " \times 21 "$ & $10 " x 24 "$ & $10 " x 27 "$ & $10 " \times 30 "$ \\
\hline & \multicolumn{7}{|c|}{ REINFORCEMENT, $\mathrm{in}^{2} / \mathrm{in}$} \\
\hline 7 & 0.008 & 0.008 & 0.008 & 0.008 & 0 & 0 & 0 \\
\hline 10 & 0.008 & 0.008 & 0.008 & 0.008 & 0.008 & 0.008 & 0.008 \\
\hline 13 & 0.015 & 0.008 & 0.008 & 0.008 & 0.008 & 0.008 & 0.008 \\
\hline 16 & 0.022 & 0.014 & 0.009 & 0.008 & 0.008 & 0.008 & 0.008 \\
\hline 19 & 0.03 & 0.02 & 0.014 & 0.009 & 0.008 & 0.008 & 0.008 \\
\hline 22 & 0.038 & 0.026 & 0.019 & 0.014 & 0.01 & 0.008 & 0.008 \\
\hline 25 & 0.045 & 0.033 & 0.024 & 0.018 & 0.018 & 0.01 & 0.008 \\
\hline 28 & 0.053 & 0.039 & 0.029 & 0.022 & 0.017 & 0.013 & 0.01 \\
\hline 31 & 0.061 & 0.045 & 0.034 & 0.027 & 0.021 & 0.016 & 0.013 \\
\hline 34 & 0.068 & 0.051 & 0.039 & 0.031 & 0.025 & 0.02 & 0.016 \\
\hline 37 & Fail & 0.057 & 0.044 & 0.035 & 0.029 & 0.023 & 0.019 \\
\hline 40 & Fail & 0.063 & 0.05 & 0.04 & 0.033 & 0.026 & 0.022 \\
\hline 43 & Fail & 0.069 & 0.055 & 0.044 & 0.036 & 0.03 & 0.025 \\
\hline 46 & Fail & Fail & 0.06 & 0.049 & 0.04 & 0.033 & 0.029 \\
\hline 49 & Fail & Fail & 0.065 & 0.053 & 0.044 & 0.036 & 0.032 \\
\hline 52 & Fail & Fail & 0.07 & 0.057 & 0.048 & 0.04 & 0.035 \\
\hline 55 & Fail & Fail & Fail & 0.062 & 0.052 & 0.043 & 0.038 \\
\hline 58 & Fail & Fail & Fail & 0.066 & 0.055 & 0.046 & 0.041 \\
\hline 61 & Fail & Fail & Fail & 0.07 & 0.059 & 0.05 & 0.044 \\
\hline 64 & Fail & Fail & Fail & Fail & 0.063 & 0.053 & 0.047 \\
\hline 67 & Fail & Fail & Fail & Fail & 0.067 & 0.057 & 0.05 \\
\hline 70 & Fail & Fail & Fail & Fail & 0.071 & 0.06 & 0.053 \\
\hline 73 & Fail & Fail & Fail & Fail & Fail & 0.063 & 0.056 \\
\hline 76 & Fail & Fail & Fail & Fail & Fail & 0.067 & 0.059 \\
\hline 80 & Fail & Fail & Fail & Fail & Fail & 0.071 & 0.063 \\
\hline 83 & Fail & Fail & Fail & Fail & Fail & Fail & 0.066 \\
\hline 87 & Fail & Fail & Fail & Fail & Fail & Fail & 0.07 \\
\hline 90 & Fail & Fail & Fail & Fail & Fail & Fail & Fail \\
\hline
\end{tabular}

Table 3: Design of Beam for Shear

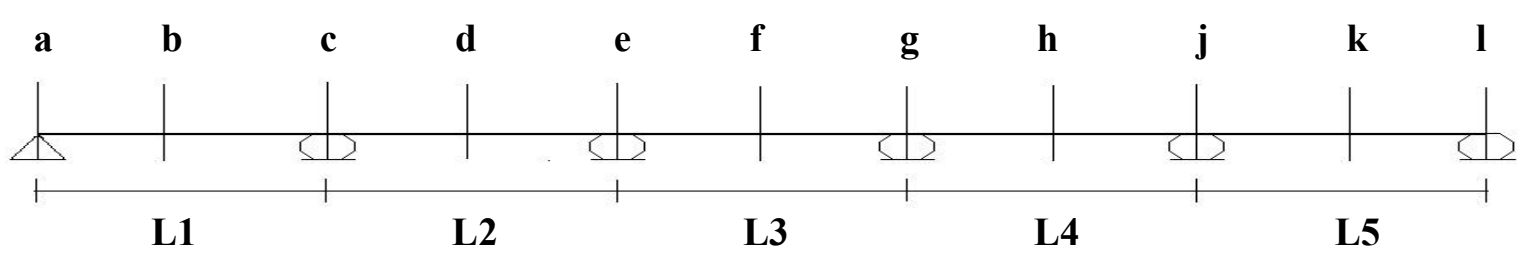

Legend

Series 1: No of Span= 5; L2/L1=1.0; L3/L2=1.0; L4/L3=1.0; L5/L4= Variable;

Series 2: No of Span= 5; L2/L1=1.0; L3/L2=1.2; L4/L3=1.2; L5/L4= Variable;

Series 3: No of Span $=5 ; \mathrm{L} 2 / \mathrm{L} 1=1.0 ; \mathrm{L} 3 / \mathrm{L} 2=1.4 ; \mathrm{L} 4 / \mathrm{L} 3=1.4 ; \mathrm{L} 5 / \mathrm{L} 4=$ Variable;

Series 4: No of $\mathrm{Span}=5 ; \mathrm{L} 2 / \mathrm{L} 1=1.2 ; \mathrm{L} 3 / \mathrm{L} 2=1.0 ; \mathrm{L} 4 / \mathrm{L} 3=1.0 ; \mathrm{L} 5 / \mathrm{L} 4=$ Variable;

Series 5: No of Span $=5 ; \mathrm{L} 2 / \mathrm{L} 1=1.2 ; \mathrm{L} 3 / \mathrm{L} 2=1.2 ; \mathrm{L} 4 / \mathrm{L} 3=1.2 ; \mathrm{L} 5 / \mathrm{L} 4=$ Variable;

Series 6: No of Span $=5 ; \mathrm{L} 2 / \mathrm{L} 1=1.2 ; \mathrm{L} 3 / \mathrm{L} 2=1.4 ; \mathrm{L} 4 / \mathrm{L} 3=1.4 ; \mathrm{L} 5 / \mathrm{L} 4=$ Variable;

Series 7: No of Span $=5 ; \mathrm{L} 2 / \mathrm{L} 1=1.4 ; \mathrm{L} 3 / \mathrm{L} 2=1.0 ; \mathrm{L} 4 / \mathrm{L} 3=1.0 ; \mathrm{L} 5 / \mathrm{L} 4=$ Variable;

Series 8: No of Span $=5 ; \mathrm{L} 2 / \mathrm{L} 1=1.4 ; \mathrm{L} 3 / \mathrm{L} 2=1.2 ; \mathrm{L} 4 / \mathrm{L} 3=1.2 ; \mathrm{L} 5 / \mathrm{L} 4=$ Variable;

Series 9: No of Span $=5 ; \mathrm{L} 2 / \mathrm{L} 1=1.4 ; \mathrm{L} 3 / \mathrm{L} 2=1.4 ; \mathrm{L} 4 / \mathrm{L} 3=1.4 ; \mathrm{L} 5 / \mathrm{L} 4=$ Variable; 


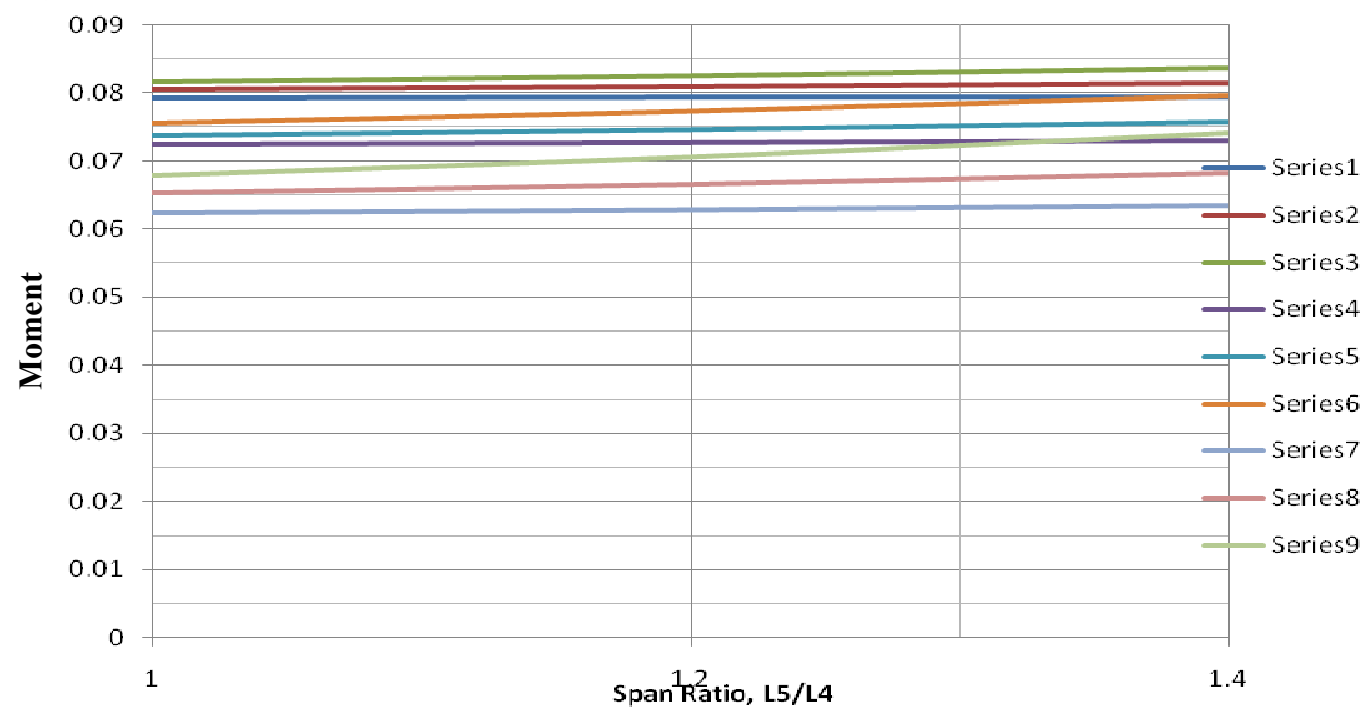

Fig 1: Moment Coefficient for Mid Span of Span L1 (location b) against Span Ratio, L5/L4

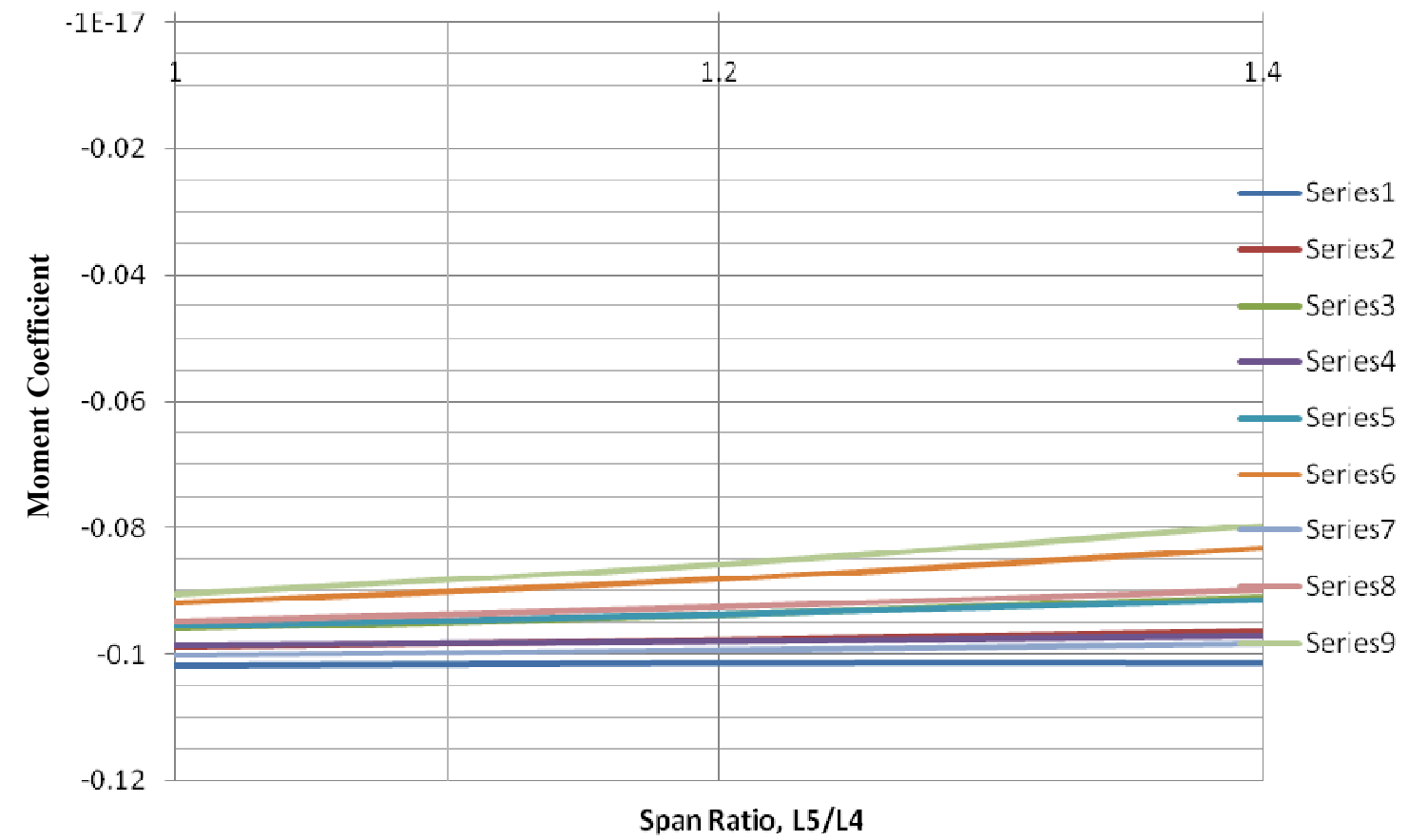

Fig 2: Moment Coefficient for support between Span L1 and L2 (location c) against Span Ratio, L5/L4 


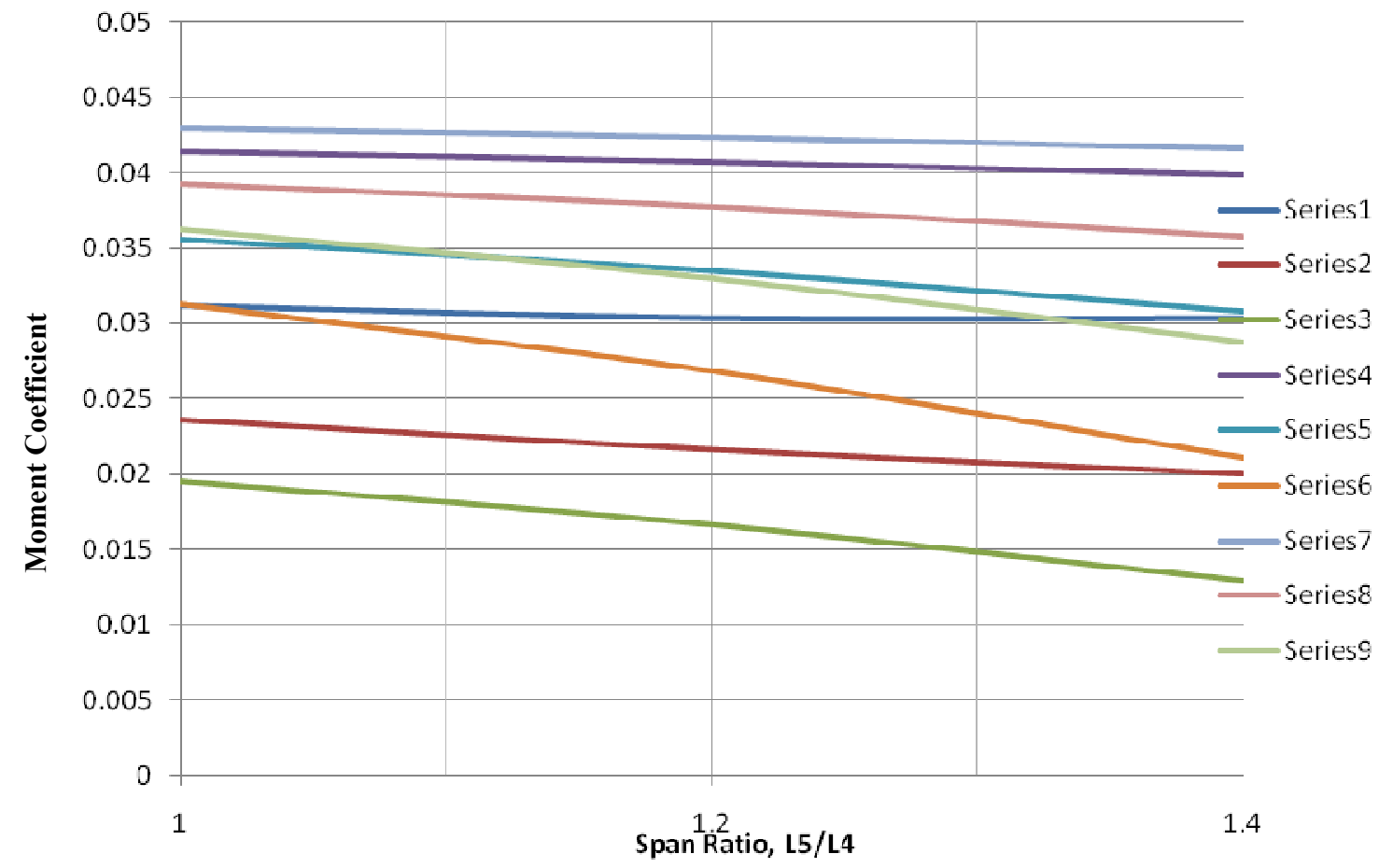

Fig 3: Moment Coefficient for Mid Span of Span L2 (location d) against Span Ratio, L5/L4

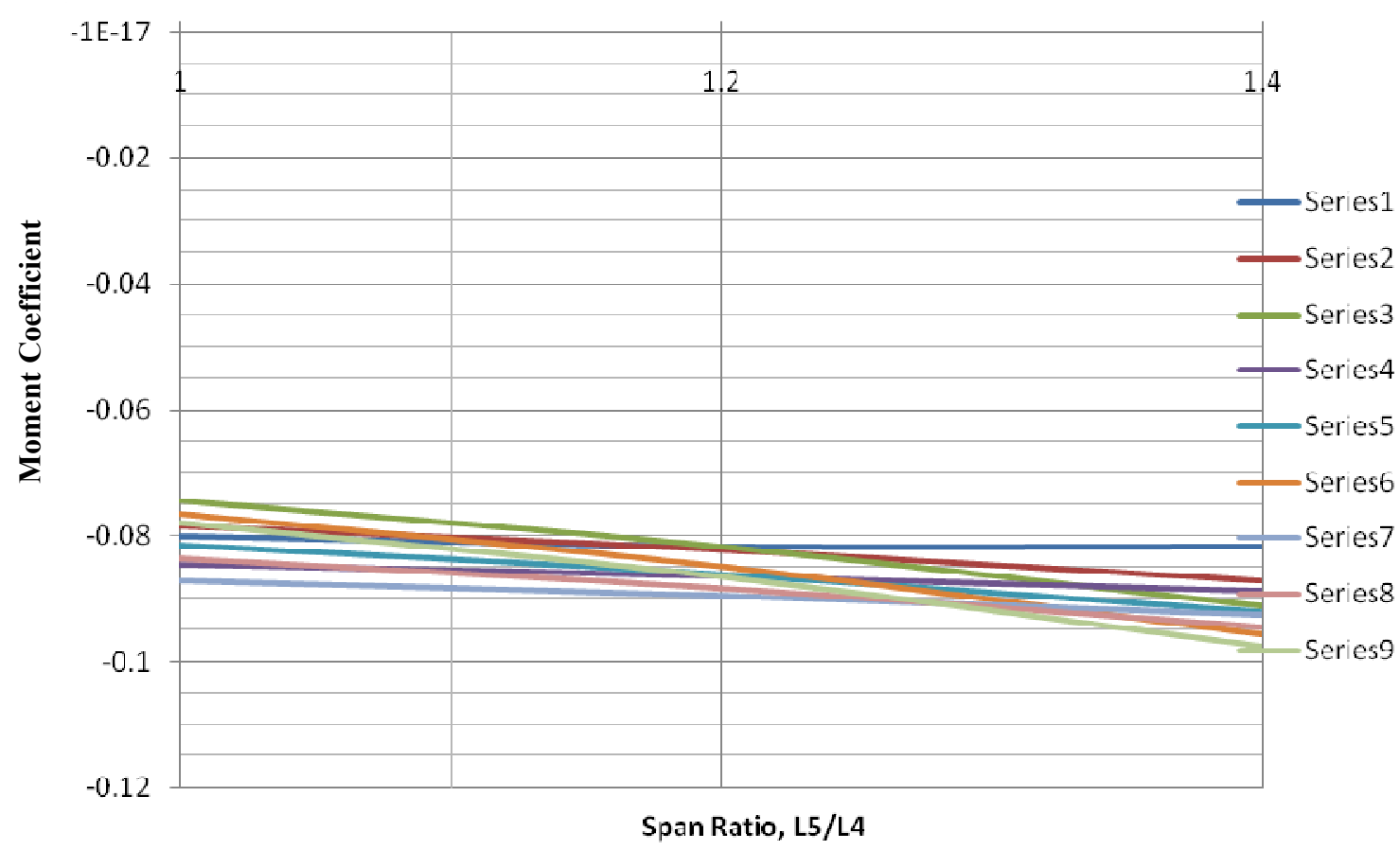

Fig 4: Moment Coefficient for support between Span L2 and L3 (location e) against Span Ratio, L5/L4 


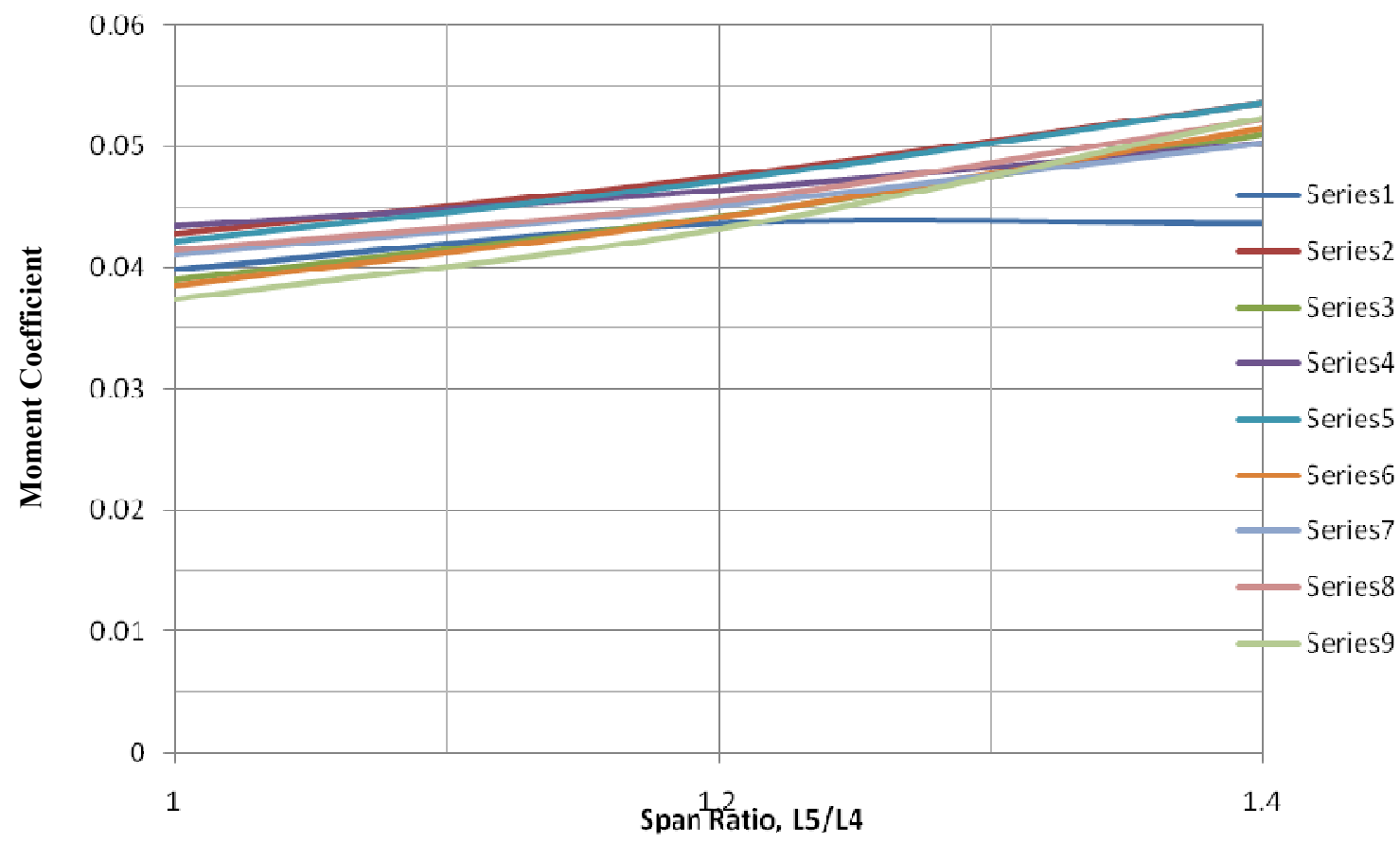

Fig 5: Moment Coefficient for Mid Span of Span L3 (location f) against Span Ratio, L5/L4

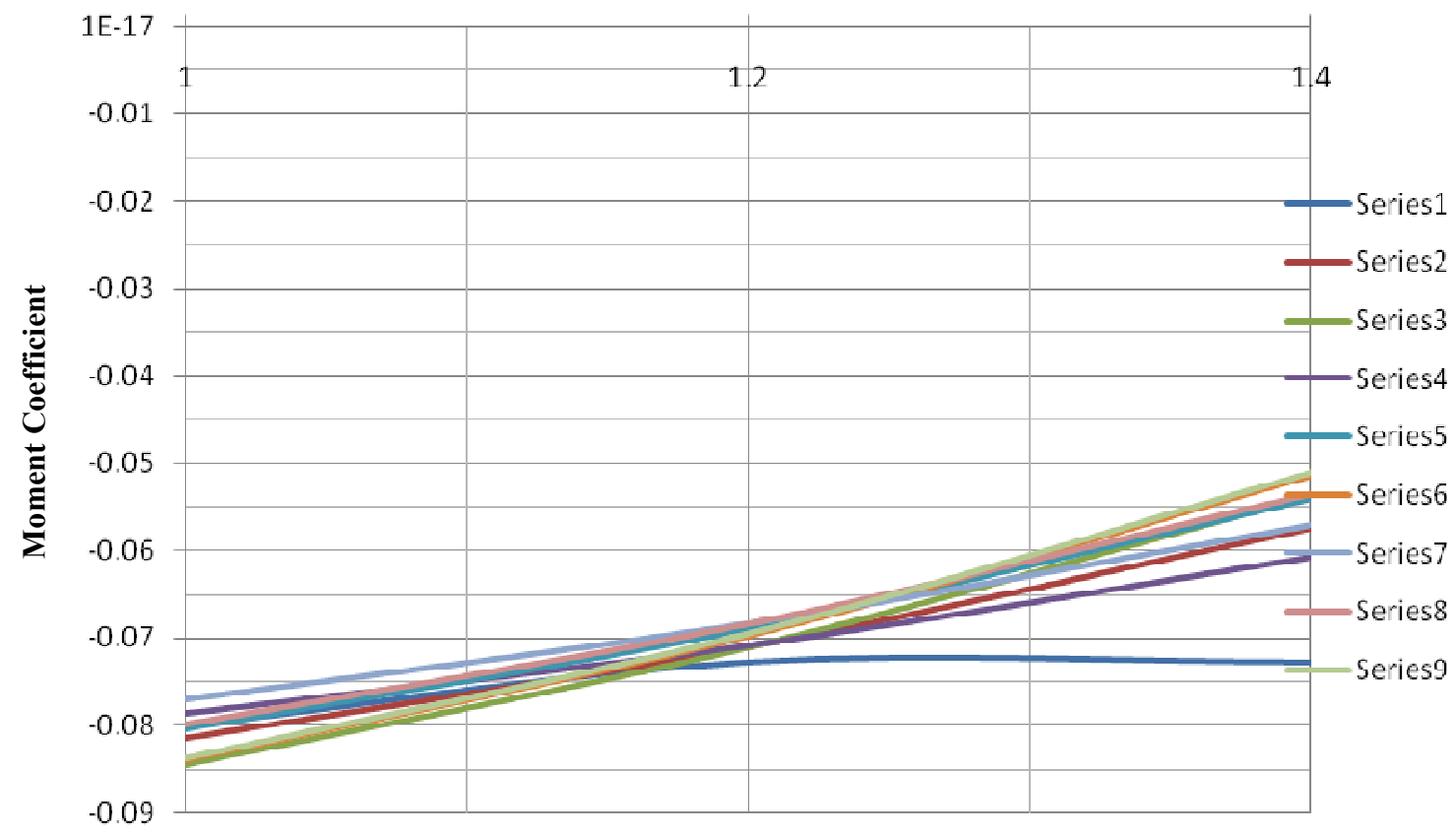

Span Ratio, L5/L4

Fig 6: Moment Coefficient for support between Span L3 and L4 (location g) against Span Ratio, L5/L4 


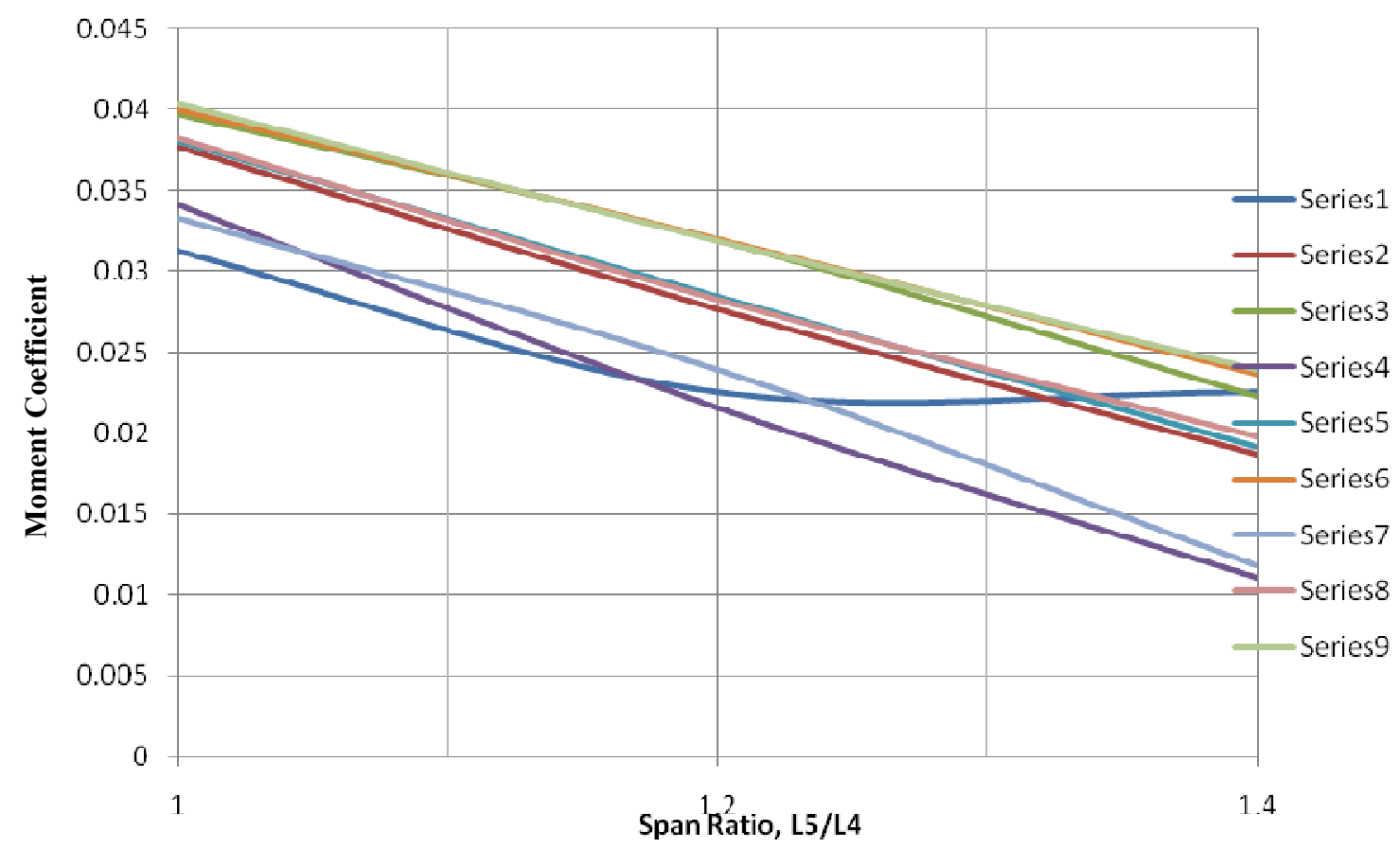

Fig 7: Moment Coefficient for Mid Span of Span L4 (location h) against Span Ratio, L5/L4

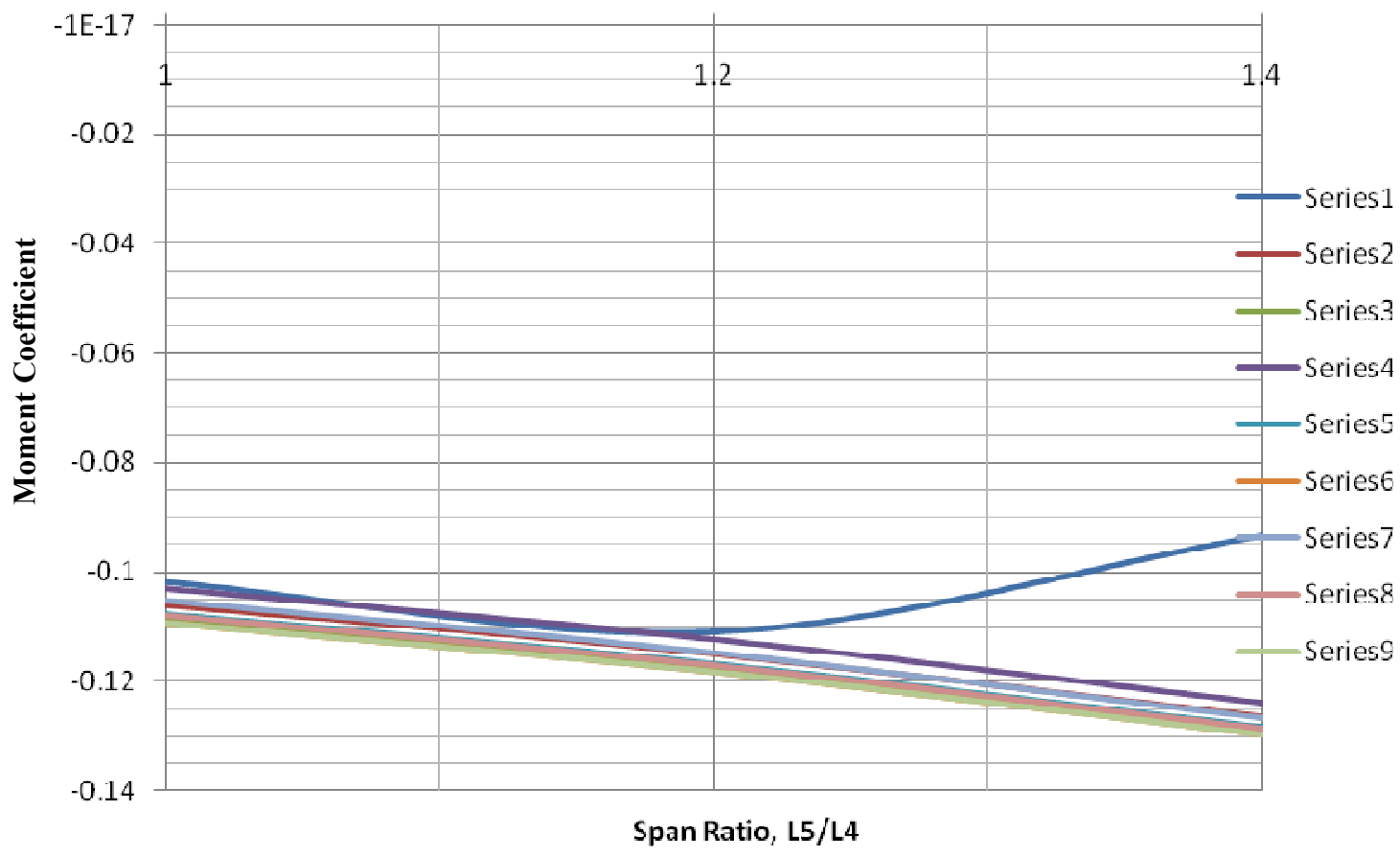

Fig 8: Moment Coefficient for support between Span L4 and L5 (location j) against Span Ratio, L5/L4 


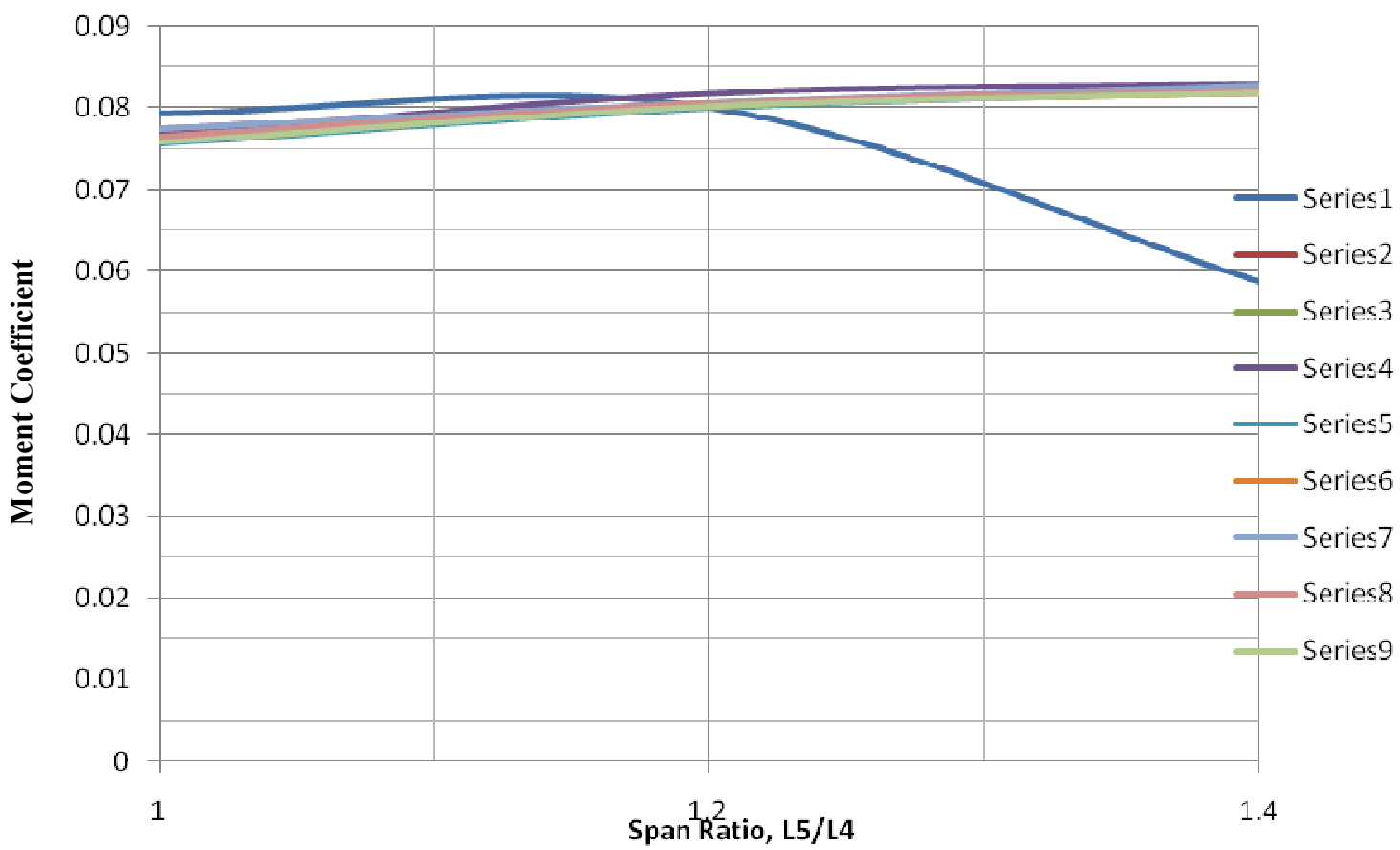

Fig 9: Moment Coefficient for Mid Span of Span L5 (location k) against Span Ratio, L5/L4 


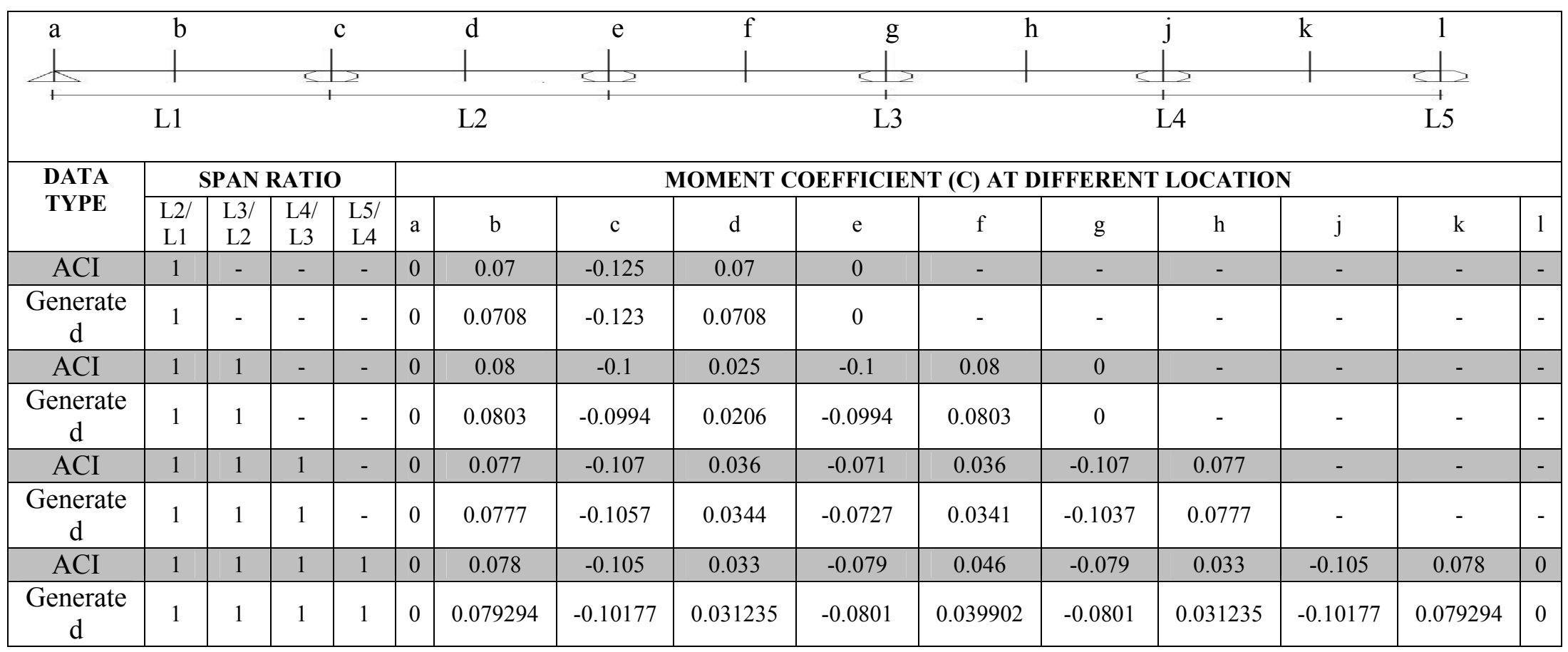

Table 4: Comparison of Generated and Available Moment Coefficients

\begin{tabular}{|c|c|c|c|c|c|c|c|c|c|c|c|c|c|c|c|}
\hline \multirow{4}{*}{$\begin{array}{r}\text { SPAN } \\
\text { RATIO }\end{array}$} & \multicolumn{15}{|c|}{ BEAM CROSS SECTION } \\
\hline & \multicolumn{5}{|c|}{$10 " \times 12 "$} & \multicolumn{5}{|c|}{$10 " x 18 "$} & \multicolumn{5}{|c|}{$10 " x 24 "$} \\
\hline & \multicolumn{5}{|c|}{$\begin{array}{c}\text { Moment Coefficients }(C) \text { at } \\
\text { Different Location }\end{array}$} & \multicolumn{5}{|c|}{$\begin{array}{l}\text { Moment Coefficients }(C) \text { at } \\
\text { Different Location }\end{array}$} & \multicolumn{5}{|c|}{$\begin{array}{l}\text { Moment Coefficients (C) at } \\
\text { Different Location }\end{array}$} \\
\hline & $\mathrm{a}$ & $\mathrm{b}$ & $\mathrm{c}$ & $\mathrm{d}$ & e & $\mathrm{a}$ & $\mathrm{b}$ & $\mathrm{c}$ & $\mathrm{d}$ & e & $\mathrm{a}$ & $\mathrm{b}$ & $\mathrm{c}$ & $\mathrm{d}$ & e \\
\hline 1 & 0 & 0.0704 & -0.1241 & 0.0704 & 0 & 0 & 0.0708 & -0.123 & 0.0708 & 0 & 0 & 0.0714 & -0.1215 & 0.0714 & 0 \\
\hline 1.2 & 0 & 0.0584 & -0.1273 & 0.0754 & 0 & 0 & 0.0588 & -0.1264 & 0.0757 & 0 & 0 & 0.0595 & -0.1251 & 0.076 & 0 \\
\hline 1.4 & 0 & 0.0424 & -0.1347 & 0.0801 & 0 & 0 & 0.0429 & -0.1339 & 0.0803 & 0 & 0 & 0.0436 & -0.1327 & 0.0807 & 0 \\
\hline 1.6 & 0 & 0.0312 & -0.1443 & 0.0814 & 0 & 0 & 0.0315 & -0.1435 & 0.0816 & 0 & 0 & 0.0319 & -0.1424 & 0.0819 & 0 \\
\hline 1.8 & 0 & 0.0192 & -0.155 & 0.0818 & 0 & 0 & 0.0195 & -0.1542 & 0.082 & 0 & 0 & 0.02 & -0.1532 & 0.0823 & 0 \\
\hline 2 & 0 & 0.0053 & -0.1661 & 0.0826 & 0 & 0 & 0.0056 & -0.1653 & 0.0828 & 0 & 0 & 0.0061 & -0.1643 & 0.083 & 0 \\
\hline
\end{tabular}

Table 5: Variation of Moment Coefficient for Cross Section Variation 


\subsection{Limitations OF The STUDY}

i. For determining moment coefficients beams of cross section of 10x18 inch. has been used. For small variation of cross section the obtained moment coefficients may be used. But for large variation moment coefficients may vary from those obtained from the analysis.

ii. Span length of the first span has always been considered to be $10 \mathrm{ft}$. The other span lengths are obtained using the first span length and span ratio. The affect of span length on moment coefficients for two span and three span beams are negligible. But for four span and five span beams moment coefficient is much affected by span length.

iii. For analysis of continuous beams span ratio has been set from 1 to 2 with variation of 0.2 . For a span ratio lying within the above range moment coefficients may be calculated by interpolation from table of moment coefficients or from graph.

iv. Moment coefficient has been obtained considering hinge support at both exterior spans of the analyzed continuous beams. But for fixed support at exterior spans moment coefficient will vary from the obtained moment coefficients.

v. The obtained moment coefficients can be used to determine moment of continuous beams for uniformly distributed load only. For point loads the obtained coefficients are not applicable.

vi. Moment coefficient has been obtained considering similar cross section at all the spans. For varying cross section at different spans for the same continuous beam, moment coefficients may vary.

vii. In the design of beam for moment and shear the strength of concrete fc' has been considered to be $3 \mathrm{ksi}$. With the variation of the strength of concrete fc', design will vary.

viii. In the design of beam for moment and shear the strength of steel fy has been considered to be 60 ksi. With the variation of the strength of steel fy, design will vary.

ix. In the design of beam only ACI-99 design code has been followed.

\subsection{CONCLUSIONS}

The following conclusions are drawn from the conducted work:

i. Analysis aid for determining moments in continuous beams up to five spans has been developed. ii. Moment coefficients are presented in this study for ranges of parameters exceeding those of ACI. In this study, moment coefficients are developed for consecutive span ratio up to 2 varying in a set of 0.2 to 1.0 .

iii. Moment coefficients developed in this study are compared with those available in ACI and a good agreement was found. However ACI coefficients are found to be more conservative.

iv. Design charts are developed for selection of beam section and reinforcement when the beam moment is available.

v. Design charts are also provided of selection of beam cross section and shear reinforcement when the design shear is known.

vi. Influence of cross section on moment coefficients has been found to be negligible.

\section{RECOMMENDATIONS FOR FUTURE STUDY}

Future study may be conducted on the coefficients of continuous beams for the following cases:

i. Development of moment coefficient when loads are not uniformly distributed.

ii. Generation of moment coefficients for lateral load in frames.

iii. Development of moment coefficients for point loads.

iv. Development of moment coefficient for varying cross section at different span for the same continuous beam.

\section{REFERENCES}

[1] Nilson A.H. and Darwin D., 1997, Design of Concrete Structures, McGraw-Hill, $12^{\text {th }}$ Edition.

[2] Winter G., Urquart L.C., O'Rourke C.E. and Nilson A.H., 1979, Design of Concrete Structures, McGraw-Hill, $7^{\text {th }}$ Edition.

[3] Wang C.K., 1983, Intermediate Structural Analysis, McGraw-Hill.

[4] Norris C.H., Wilbur J.B. and Uktu S., 1991, Elementary Structural Analysis, McGraw-Hill, $4^{\text {th }}$ Edition.

[5] Reynolds C.E. and Steedman J.C., 1988, Reinforced Concrete Designer's Handbook, E \& FN Spon, $10^{\text {th }}$ Edition. 